\title{
Tourology: An Integrated Approach to Tourism Itineraries*
}

\author{
Stefano Soglia**
}

\begin{abstract}
The recent fast-paced evolution of the travel itinerary has resulted in an increasingly complex tourist product. A greater understanding of this evolution is essential for the appropriate development of tourist destinations. New technologies and the growing interest in customised authentic travel experiences are also redefining the concept of the travel itinerary. This makes the planning and management of itineraries even more complex, and has led to the recognition of a new discipline in the field of tourism: tourology.
\end{abstract}

Keywords: Global Tourism; Tourism Destination; Tourism Marketing; Tourism New Technologies; Travel Experience

\section{Current Itineraries}

The word itinerary comes from the Latin itinerarium, an ancient Roman road map that noted the distances between cities. The word itinerarium itself is derived from iter and itineris, i.e., a route, a journey or a path.

The itinerary is one of the most characteristic aspects of travel, dating back to the dawn of tourism, around $3000 \mathrm{BC}$. It is one of the three basic tourism products, together with permanent products (archaeological sites, museums, landscapes, etc.) and temporary products (events, sports, culture, business, etc.) ${ }^{\mathrm{i}}$.

Itineraries are universal tourist attractors, and usually include a series of particular individual attractions (identified as stops or nodes). However, a well-planned itinerary is far more than a simple summation of the individual nodes: once the itinerary has been identified, it suffuses the nodes with new meaning, and helps to construct a new identity for the entire territory through which it flows.

In recent years tourist itineraries have taken on different connotations and strengthened their role in destination management policies. While these developments are significant, some models of themed itineraries, such as food and wine routes ${ }^{\mathrm{ii}}$, have become even more firmly established. Furthermore, regulatory developments over the last few decades have favoured the establishment of public-private partnerships in the drawing-

${ }^{*}$ Invited Article

** Marketing and Tourism Consultant (info@stefanosoglia.info)

Edited by: ISTEI - University of Milan-Bicocca

ISSN: 1593-0319

Soglia, S. (2017). Tourology: An Integrated Approach to Tourism Itineraries, Symphonya. Emerging Issues in Management (symphonya.unimib.it), 3, 71-80. 
up of itineraries. While state support during the start-up phase of many recent Italian itinerary planning projects has been sorely lacking, this has not diminished the (arguably inevitable) validity of the territorial network model for local development. These itineraries have proven to be a successful strategic model.

In summary, from the many successful experiences of the last decades, it can be said that itineraries:

- lead to the creation of specific jobs (guides, etc.),

- stimulate trade and encourage the establishment of services (e.g. equipment rentals and sales),

- offer a model of aggregation for operators, thus strengthening the tourist-territory supply system,

- attract public investment (e.g. cycle paths) and private investment (e.g. cyclingoriented facilities).

While there are many operators who treat itineraries as a major product (e.g. U.K. tour operators specializing in bike or wine tourism), there is currently no specific promotional trade event focused on this sector, despite the fact that the importance attributed to tourist itineraries has been steadily growing. This growth is reflected in projects such as:

- the signing of Ministerial-Regions Protocols in July 2016, which provide for the allocation of 91 million Euros over the three-year period 2016-2018 for the development of 3 cycle paths of national interest, with a total length of over 1,500 kilometres ${ }^{\mathrm{iii}}$;

- the submission to UNESCO of a proposal to recognise the Italian stretch of the Via Francigena as a World Heritage Site ${ }^{\mathrm{iv}}$, on the part of the regions involved, and;

- on-going initiatives celebrating the bicentenary of the publication of Goethe's Italian Journey, and the related proposals to recognise this Grand Tour as an official Council of Europe itinerary.

Each itinerary has its own genesis, and is the result of a combination of local regulations, the interests and specializations of the people who put the itinerary together, territorial peculiarities, and overarching theme (e.g. pilgrimages, bike tourism, etc.).

Compared with other areas of tourism (such as hotel management, event organization, or the management of cultural or sustainable tourism), there are still very few studies or methodologies which could constitute a systematic point of reference for itineraries, with the notable exception of a small body of research and publications by professor Fiorella Dallari at the University of Bologna and a few others. This lack of research makes it difficult to move beyond simple descriptions of themed itineraries or travel proposals.

\section{Towards a Taxonomy of the Itinerary}

Itineraries are both a mind-set and a sociological phenomenon: they have to take multiple requirements into account, including optimization of travel time and costs, maximization of sites and experiences along the route, reduction of risks and disruption, the emulation of previous travellers, and so on.

Over time, therefore, they tend to evolve depending on the changing preferences of the traveller, and the logistical conditions that are placed upon them. At the end of the 19th 
century, for example, it was particularly difficult to travel by land in much of Italy, because of the lack of adequate infrastructure, making it hard to imagine itineraries appertaining to the hinterland. In this period, the now celebrated Tuscan landscape of the Val d'Orcia was perceived as inhospitable and devoid of aesthetic interest by contemporary travellers such as Elizabeth Pennell, who cycled from Florence to Perugia and then on to Rome accompanied by her husband on a tandem tricycle.

In the present postmodern era, characterized by the coexistence of multiple ways of dissolving old marketing concepts in favour of maximum customization, it has become necessary to formulate a response to diametrically opposed and often irreconcilable tourism trends, including:

- the growth of 'fake' destinations (from the Venices, complete with gondolas, recreated in China in the city of Dalian and in the Macau region, to Ferrari Land, a recent addition to Spain's PortAventura theme park);

- the search for authenticity in the travel experience, and full immersion in the territorial context, where the word 'local' is used as a sort of password, and Airbnb is seen as the best solution for travelling in the sharing economy.

This latter trend is reminiscent of the type of tourist-travellers defined as 'allocentric' by Plog (1974). Allocentric tourist-travellers are looking for the traditions of a country, seeking how life was lived in the past. This includes activities such as trekking with donkeys in the Apennines, or transhumance with shepherds in the Abruzzo hinterland.

At first glance an itinerary is simply a path that links several points of interest, but in broader terms it can be considered as an economic-cultural package, a local development tool, and a tourist product.

In more evocative terms, Raffaele Milani defines an itinerary as “... a psychic process unifying the aesthetic experience, both as an act of the senses and as an act of feeling”.

From a traditional perspective, an itinerary is made up of three basic elements:

a. Nodes: stages, places worth visiting, stop points that also serve a logistical function (from the horse exchange stops at old mail stations to contemporary charging points for ebikes). The nodes are represented by the letters A to F in the diagram.

It should be noted that on hiking routes (e.g. mountain biking or trekking), the landscape and the itinerary are themselves the main attraction, and the nodes may be areas of outstanding natural beauty and recommended viewpoints, peaks or intersections dictated by the lay of the land.

b. Links: the connections between nodes. These are not necessarily the shortest distance from one node to another: rather, factors such as the safety of the route (e.g. family cycle paths) and the beauty of the landscape are taken into consideration. For this reason, an itinerary cannot be automatically generated by a GPS system, which is designed to optimize distance and travel time parameters.

Figure 1: A Taxonomy of the Itinerary 


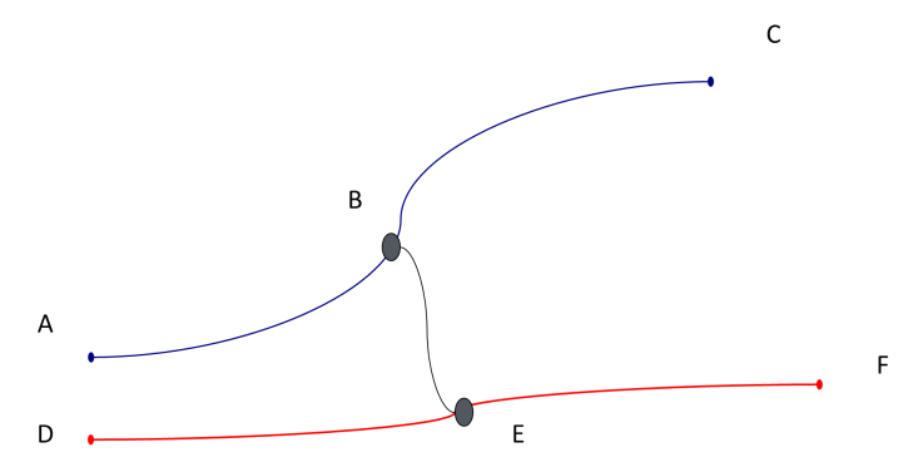

In the diagram the links are represented by the segments A-B, D-E and so on.

Note, however, that the segment B-E can also be defined as a bridge. This is a link between two itineraries with different themes or features, when the two nodes $\mathrm{B}$ and $\mathrm{E}$ meet or cross, for example, at an info point in the centre of a city, or at any point along the route of two itineraries (as in Siena near Porta Romana, where the Via Francigena and the Eroica route intersect). A bridge may also be virtual.

c. Theme: The third element of an itinerary is the thematic, the common element that gives the choice of nodes and links meaning. The theme is what sets any particular itinerary apart, making it unique. The name of the itinerary should synthesize the theme. The success of an itinerary depends on how appealing the theme is, and how well the theme is reflected in its appellation. While devising an itinerary it is important to be wary of the temptation to imitate themes that may have worked in other territories, but which may not be suitable in the present case, or themes that were successful because they followed contemporary trends, which may no longer be applicable. It can also be tempting to try to wrestle a single generic theme from the nodes and links available, which actually have little to do with each other, or which may prove to be impractical.

Taking these basic elements as a starting point, we can now consider the classic typological division of itineraries, which are distinguished by the form they take. These forms are often combined in complex and medium-long journeys.

- Linear

Monodirectional: owing to orographic factors (e.g. downhill based on the direction of a river) or thematic considerations (e.g. pilgrimages to a sacred place, such as Rome or Mecca), this type of itinerary always follows the same direction.

Symmetric: this itinerary can be followed in both directions indiscriminately, and therefore the starting point and destinations may vary (e.g. Romantische Strasse Würzburg-Füssen ${ }^{v}$ ).

- Circular: the starting point coincides with the point of arrival at the end of the tour, which may take place over several days, thereby requiring intermediate stages where travellers stay for a limited time (one or more nights, requiring luggage and check-in / out). 
- Daisy: with a central hub to be used as a base for several days, the starting point for various excursions (petals). This is the typical model for hiking in the mountains or cycling at seaside resorts (e.g. Riccione Bike hotels).

These categories imply that the word itinerary can assume very different meanings for a travel agent, a hiking guide, a runner participating in a race, or a family on vacation looking for locations related to the Harry Potter saga. It is therefore necessary to go into greater detail in order to further define the multiple meanings of the term itinerary.

In his 2015 book, Giovanni Serafino (an incoming tour operator in Puglia) distinguishes two types of itinerary: promotional itineraries, designed by public bodies to promote local attractions, and commercial itineraries, designed by tour operators to create new products to be sold on the tourism market.

I would like to take this further, and propose the adoption of the following subdivision, distinguishing 4 types of itineraries:

\section{A. Permanent}

A1. Historical walkways and roads (tendentially linear, such as religious itineraries ${ }^{\mathrm{vi}}$ ) and thematic routes (e.g. wine and food routes, Bavaria's Romantic Road etc.).

A2. Hiking trails (by car, bike, motorbike, ebike, walking, horse, etc.). These are typically short-range and naturalistic.

\section{B. Temporary}

B1. Travel programs, primarily determined on the basis of the available infrastructure and specific packaging of tour operators and travel agencies on behalf of individual customers.

B2. Event-routes (historical re-enactments, sports competitions, etc.)

While permanent itineraries are endowed with services (e.g. transport), permanent infrastructure and adequate road signage ${ }^{\text {vii }}$, which makes them accessible autonomously and at any time even by self-organized tourists, temporary itineraries are particularly interesting because of their improvised nature, making them adaptable to the needs of the moment. This itinerary customization is increasingly appreciated by tourists who, although they do not want to miss visiting the must-sees of a destination (e.g. Venice, Florence, and Rome for the typical foreign tourist), greatly appreciate the originality of a travel program that includes stages in unusual but characteristic and little-known places. This approach is what characterizes the American tour operator Rick Steves, author of the 'Italy Through the Back Door' travel guides. These guides have made the combination of celebrated destinations and stops in small lesser-known Italian towns the key to their success.

Successful examples of event routes often feature a hybridization phenomenon: itineraries created around annual sports events, festivals or anniversaries can capitalise on the fame of the event to move beyond it and transform into permanent itineraries where tourists can follow an itinerary designed around a historical event or a fictional character. Examples of this phenomenon include the stages of the Tour de France, the Stelvio Pass, and the Eroica route. In a few short years, the Eroica historical bicycle race 
has moved beyond its home in Siena and now organises successful Eroica events all over the world, exporting its own unique brand of historical racing.

\section{Towards Tourology}

While in the past it was necessary (or at least advisable) to follow precise itinerary packages, new geonavigation technologies and transport mode options for moving between and within various itineraries have led to a dissolution of the traditional concept of the itinerary, with its predefined links and nodes.

This phenomenon is associated with the increasing importance of the role of the character, whether real or fictional, in tourism, beyond the traditional role of place (as indirectly illustrated by the growing interest in events like Bologna's Biografilm Festival). Character is the mediator of place, a testament of a life that piques our curiosity and engages us, or that we may aspire to emulate. By identifying with this person to an extent permitted by the suspension of disbelief typical of tourism, visitors can leave behind their everyday role in life and assume a different identity. The Bologna tour operator Destinazione Umana (Human Destination) specialises in this concept, and has proved its worth as an effective differentiation strategy.

Taking the above into account, and taking note of the on-going development of established itineraries in the traditional sense, it is worth considering how the concept of the itinerary is dissolving and becoming an increasingly personal and personalised experience, thanks in part to advances in technology and mass customisation systems.

Operationally, the planning of the tourist itinerary must provide for harmonisation between two spheres of interest that may initially appear contradictory:

- a quantifiable sphere with elements that can be mathematically optimised (for example, putting together itineraries adapted to the target user and/or briefer experiences with an origin and a destination);

- a less-easily quantifiable sphere, including elements whose optimisation is based on subjective opinion (for example, identifying the "most beautiful" itineraries, or the promotion of places which are less well-known or more difficult to reach, which can make a bigger impression than more famous destinations precisely because they are off the beaten track).

The conciliation of these different spheres allows for the elimination of the least appropriate solutions, meaning we can outline the remaining, feasible solutions in a set of possible alternatives and itinerary proposals that satisfy efficiency criteria, taking constraints and objectives into account.

In light of these developments it is worth considering the noted subdivision proposed by Jan Der Borg (Università di Cà Foscari) on the modality of promoting territories. It seems apparent that the planning of itineraries (particularly permanent itineraries) should now favour the Pinball model, concentrating on the nodes rather than the links. 
Predefined itineraries (such as the Grand Tour) are only appropriate for dense node clusters with steady demand flows, and require complex services (e.g. guided tours, parking, public transport, and so on).

Figure 2: Emphasis on Nodes and Links
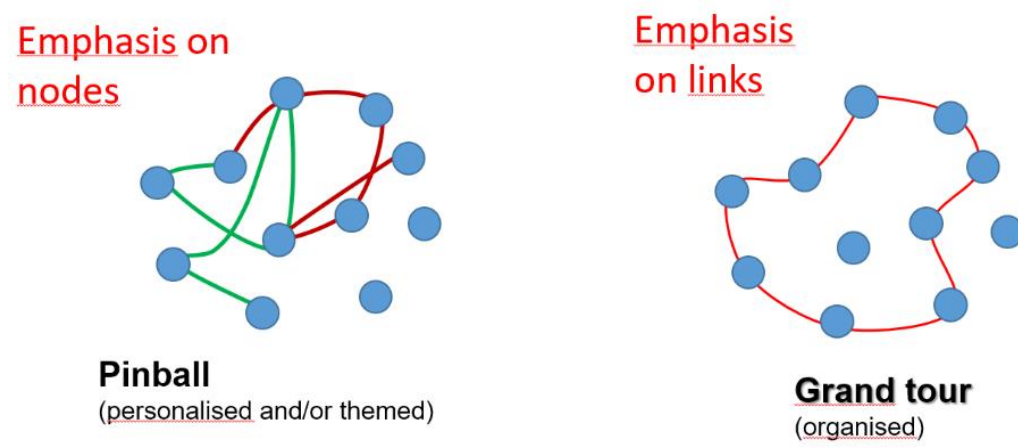

'Pinball' itineraries are not predefined. By utilising technology, they are particularly adapted to new thematic tourism approaches focused on testimonial experiences (e.g. Harry Potter, Shakespeare or Jane Austen tours in Great Britain) where the character is at the centre of a trip that is inspired by real or fictional people.

For territories with widespread attractions, which are the majority of Italian tourist areas outside the great cities of art and single-point attractions (e.g. archaeological sites), it would therefore be wise to favour territorial surfing, so that the tourist, having entered the territory, can move freely, as though they are bouncing around a sort of enormous pinball table, where every location opens up the prospect of new locations, thus giving the trip greater significance, and improving the experience.

So, is it a case of "the itinerary is dead: long live the itinerary"? In a certain sense, yes, it is. If used strategically, the new technologies allow us to:

-geo-reference locations, using, for example, QRcodes, and the visitors' own devices, allowing them to enjoy the itineraries more easily;

-create something that could not exist without the use of multimediality, allowing visitors to really connect with a character (real or fictional as the case may be);

-share this consciousness and create 'communities of meaning' thanks to the asynchronous collective fulfilment generated by social networks, blogs and so on.

Some start-ups are already making their mark in this field, primarily in the Italian market at present, but with potential for international expansion. These include True Places (created by Vivara Viaggi ${ }^{\text {viii }}$ to enable the real-time formulation of personalised itineraries while highlighting stand-out destinations along the route) or the 'smart' guided tour system WeHare (see www.guide.wehare.com for details). These systems are among the more than 100 Italian start-ups associated with Start-Up Turismo (see www.startup-turismo.it for the latest developments in new technologies being applied to itinerary planning). 
From these initial reflections it is clear that the planning of an itinerary is a complex operation that requires a systematic and interdisciplinary approach. The principal sectors and areas of expertise necessary for the study and planning of tourist itineraries are as follows:

-tourism geography,

-tourism economics and marketing,

-destination management and tourism intermediation,

-IT and GIS ${ }^{\text {ix }}$,

-urban and regional development,

-aesthetics and landscapes,

-experts (tourist guides, product technicians, sports stars, journalists, etc.).

Tourology is a neologism coined to identify the discipline in the field of tourism that is concerned with analysis, planning methodologies and itinerary management. Thus the tourologist is the person involved in various different aspects of tourism itineraries, who works in tourology in the public and private sectors.

Tourology - the result of a convergence of academic research in the tourism sector and specialists dedicated to tourism itineraries - leads beyond merely describing the multiplicity of individual itineraries. There is no shortage of texts about single itineraries (particularly the better known ones, or those promoted by the Council of Europe). Tourology offers the possibility of a comprehensive interdisciplinary approach, to better face the growing challenges of this strategic area of tourism development.

To this end, it is to be hoped that an academic-professional network can soon be established in order for the figure of the tourologist to be recognised professionally. This could also give rise to specialist publications and specialized services for the use of tourist operators and public administrators.

\section{Bibliography}

Bellini, N., \& Convert, L. (2016). The Concierge. Tradition, Obsolescence and Innovation in Tourism, Symphonya. Emerging Issues in Management (symphonya.unimib.it), 2, 17-25.

http://dx.doi.org/10.4468/2016.2.03bellini.convert

Brondoni, S. M. (2016). Global Tourism Management. Mass, Experience and Sensations Tourism, Symphonya. Emerging Issues in Management (symphonya.unimib.it), 1, 7-24.

http://dx.doi.org/10.4468/2016.1.02brondoni

Corti, A. (2016). Global Tourism New Volatility, Old Statistics, Symphonya. Emerging Issues in Management (symphonya.unimib.it), 1, 25-30.

http://dx.doi.org/10.4468/2016.1.03corti

Council of Europe (2011), Impact of European Cultural Routes on SMEs' Innovation and Competitiveness, http://www.coe.int

Franzoni S. \& Pelizzari C. (2016) Weather Risk Management in Tourism Industry, Symphonya. Emerging Issues in Management (symphonya.unimib.it), 1, 45-55.

http://dx.doi.org/10.4468/2016.1.05franzoni.pelizzari 
Gnecchi, F., (2009). Market-Driven Management, Market Space and Value Proposition, Symphonya. Emerging Issues in Management (symphonya.unimib.it), 2, 33-45

http://dx.doi.org/10.4468/2009.2.04gnecchi

Lozato-Giotart J. P. (2003), Géographie du tourisme. De l'espace consommé à l'espace maitrisé, published by Pearson Education France

Mosca, F., Ben Youssef K., \& Majd, T. (2016). Online Communication and Italian Tourism, Symphonya. Emerging Issues in Management (symphonya.unimib.it), 2, 31-45.

http://dx.doi.org/10.4468/2016.2.05mosca.youssef.majd

Moutinho, L. (2000). Strategic Management in Tourism, CABI Publishing, New York.

Pattanaro, G., \& Pistocchi, F. (2016). Linking Destinations Through Sustainable Cultural Routes, Symphonya. Emerging Issues in Management (symphonya.unimib.it), 1, 83-96.

http://dx.doi.org/10.4468/2016.1.09pattanaro.pistocchi

Puczko L. and Ratz T. (2007), Trailing Goethe, Humbert and Ulysses tourism: cultural routes in tourism, Cultural Tourism: Global and Local Perspectives, New York

Rovai, S. (2016). Chinese Outbound Shopping Tourism: A Market-Driven Approach for the Luxury and Fashion Industry, Symphonya. Emerging Issues in Management (symphonya.unimib.it), 1, 56-63.

http://dx.doi.org/10.4468/2015.1.06rovai

Salvioni, D. M. (2016). Hotel Chains and the Sharing Economy in Global Tourism, Symphonya. Emerging Issues in Management (symphonya.unimib.it), 1, 31-44.

http://dx.doi.org/10.4468/2016.1.04salvioni

Trunfio, M., \& Della Lucia, M. (2016). Toward Web 5.0 in Italian Regional Destionation Marketing, Symphonya. Emerging Issues in Management (symphonya.unimib.it), 2, 60-75.

http://dx.doi.org/10.4468/2016.2.07trunfio.dellalucia

\section{Notes}

${ }^{\mathrm{i}}$ We could also add tourist accommodation to these three basic products, when the accommodation itself becomes a destination, as in the case of spa resorts, farm holidays, tourist villages, or any accommodation facilities that can be considered as a location or site of tourist experiences, and not just a means of providing the services (such as overnight stays and catering) necessary to the appreciation of places, events or tourist itineraries.

ii The first wine route in France (and therefore in the world in general) was created in Alsace in 1953. This $180 \mathrm{~km}$ linear road weaves through magnificent vineyards and picturesque villages situated between the Vosges mountain range and the border with Germany. In Italy, following national legislation that established the concept of wine roads and subsequent regional regulations of the late 1990s, 130 wine and food roads have been officially established. Of these, it is estimated that only around $10 \%$ are operational and continue to serve a tourism or territorial development function. These $10 \%$ tend to be those routes created in territories where the requirements for such a route actually existed (quality food and wine products, beautiful landscapes, etc.) and where people were genuinely promoting their territory, rather than merely taking advantage of the funds being made available at the time. Operational routes include the Strada del Vino Nobile di Montepulciano e dei Sapori della Valdichiana, Tuscany's first wine route, established in 1998, which has recently established its own incoming agency, to promote and market tours and tourist services.

iii These are the Vento cycle path along the Po river between Venice and Turin, the Sole cycle path between Verona and Florence, and the Acqua cycle path between Caposele in the province of Avellino and Santa Maria di Leuca in the province of Lecce. These were later joined by the Large Bicycle Ring Road (GRAB). The paths are the result of an agreement between the Ministry of Cultural Heritage and 
Activities and Tourism, The Ministry of Infrastructure and Transport and the regions of Piedmont, Veneto, Lombardy, Emilia Romagna, Tuscany, Campania, Basilicata, Puglia and the City of Rome.

iv The region of Tuscany led the accreditation project. Over $400 \mathrm{~km}$ of the Via Francigena passes through Tuscany, which has invested considerable sums in facilities for this itinerary to make it easily accessible both on foot and by bicycle.The importance of the itinerary as a tourist product for regions like this is clearly illustrated by the fact that it is estimated that, in the region of Tuscany in 2014, itineraries accounted for around $18 \%$ of total tourist flow, i.e. 3.2 million arrivals and 8 million room nights.

${ }^{v}$ This German itinerary was established in 1950. A shuttle bus runs along the $500 \mathrm{~km}$ route in both directions several times a day, providing an extremely useful service for tourists, whether they want to return to their starting point or proceed to other stages. Provisions are also made for passengers to take their bicycles.

${ }^{\mathrm{vi}}$ Religious itineraries can be divided into: - Pilgrimages undertaken with the aim of visiting symbolic religious destinations, which are the motivation for the pilgrimage, and; - Walks (such as Via Dei Pellegrini) where the route itself is important, and the destination is secondary.

It should be noted that most religious buildings are also works of art, and as such are often stages on tourist-cultural itineraries. It can be difficult to clearly distinguish the motivation of those visiting religious buildings, and thus problematic to define a particular route as specifically religious. For example, while people who walk along the Camino de Santiago are often motivated more by religious belief, the Via Francigena also has enormous appeal for hikers and cyclists seeking beautiful landscapes and unique cultural experiences.

vii Tour operators are often unappreciative of road signage that identifies an itinerary (whether it is a countryside cycle path or a city route). Given that these operators propose highly experiential journeys, they may feel that road signage reduces the role of "interpreter" of the territory, and weakens their position as a uniquely informed guide to the best route for their customers. Of course, proper location and link signage of a thematic route increases its visibility and seeks to promote it, but there is also the risk of 'vulgarization' or banalization. It is important to take these factors into account during the design phase of an itinerary, depending on the target and the pattern of use desired, in order to determine how much, or how little, to invest in road signage.

viii Tour operator who also manages the new hop-on hop-off service Discover Pavarotti and Ferrari Land in the Emilia-Romagna territory

${ }^{i x}$ Geographic Information System. GIS is a computerized information system that allows the acquisition of, recording of, analysis of, visualisation of and access to information derived from geographical data (geo-referencing). 